University of Nebraska - Lincoln

DigitalCommons@University of Nebraska - Lincoln

Sociology Department, Faculty Publications

Sociology, Department of

2001

\title{
The Effects of a High-Risk Environment on the Sexual Victimization of Homeless and Runaway Youth
}

\author{
Kimberly A. Tyler \\ University of Nebraska-Lincoln, kim@ktresearch.net \\ Les B. Whitbeck \\ University of Nebraska-Lincoln, Iwhitbeck2@unl.edu \\ Dan R. Hoyt \\ University of Nebraska-Lincoln, dhoyt2@unl.edu \\ Ana Mari Cauce \\ University of Washington
}

Follow this and additional works at: https://digitalcommons.unl.edu/sociologyfacpub

Part of the Sociology Commons

Tyler, Kimberly A.; Whitbeck, Les B.; Hoyt, Dan R.; and Cauce, Ana Mari, "The Effects of a High-Risk Environment on the Sexual Victimization of Homeless and Runaway Youth" (2001). Sociology Department, Faculty Publications. 40.

https://digitalcommons.unl.edu/sociologyfacpub/40

This Article is brought to you for free and open access by the Sociology, Department of at DigitalCommons@University of Nebraska - Lincoln. It has been accepted for inclusion in Sociology Department, Faculty Publications by an authorized administrator of DigitalCommons@University of Nebraska - Lincoln. 


\title{
The Effects of a High-Risk Environment on the Sexual Victimization of Homeless and Runaway Youth
}

\author{
Kimberly A. Tyler \\ University of Nebraska-Lincoln \\ Dan R. Hoyt \\ Les B. Whitbeck \\ University of Nebraska-Lincoln \\ Ana Mari Cauce \\ University of Washington
}

\begin{abstract}
Based on the structural-choice theory of victimization, the current study examines the effects of a high-risk environment on the sexual victimization of 311 homeless and runaway youth. Results from logistic regression revealed that survival sex, gender, and physical appearance were significantly associated with sexual victimization. Results from a series of interactions also revealed that the effects of deviant behaviors on sexual victimization varied by gender and age. Although males and females engaged in similar activities, young women were more likely to be victims of sexual assault. These findings suggest that engaging in high-risk behaviors predispose some people to greater risks but it is the combination of these behaviors with gender and/or age that determines who will become victimized.
\end{abstract}

S exual victimization varies according to the presence of risk factors. Some risk factors, according to the sexual assault literature, include gender, age, alcohol and/ or drug use, personal characteristics, and location (Abbey, Rose, McDuffie, \& McAuslan, 1996; Harney \& Muehlenhard, 1991; Vogel \& Himelein, 1995). Females are generally more likely to experience sexual victimization compared to males (Finkelhor, 1993,1994; Koss, Gidycz, \& Wisnieski, 1987). A national study of college students revealed that since the age of 14 , approximately $28 \%$ of college women reported having experienced a rape. In addition, $54 \%$ of college women reported being sexually victimized (Koss et al., 1987). The age at which victimization occurs also varies, with the greatest risk for young children occurring between 7 and 13 years of age (Finkelhor, 1994). Finkelhor and Asdigian (1996) found that age was a significant predictor of sexual victimization among 10- to 16-year olds whereby older respondents were more likely to be victims. The association between age and sexual victimization may be because teens and youth and/or young adults date frequently (Hamey \& Muehlenhard, 1991). Therefore, females in this age category (13 to 18) may be exposed to a larger number of potential perpetrators. 
Many studies of alcohol consumption and victimization found that when alcohol use increased for men and women, the likelihood that women were sexually victimized on a date also increased (Abbey et al., 1996; Vogel \& Himelein, 1995). Abbey and colleagues also argue for a situational vulnerability framework where women who date and engage in sexual activity on a regular basis increase their probability of interacting with sexually violent men. This suggests that women who drink heavily when dating are more likely to be at risk for sexual victimization. Alcohol serves as a risk factor for women because it lowers their ability to resist attack while also serving as an excuse for college men who force sex on disinterested dates. Research demonstrates (cf., Fromme \& Wendel, 1995; Martin \& Hummer, 1989) that many fraternity members reported low perceived risks associated with sexual coercion when intoxicated, due to a feeling of not being responsible for their actions.

The risk for sexual victimization also varies by location. Harney and Muehlenhard (1991) note that victimization is likely at fraternity parties, at the offender's home, in a car, or at an isolated location. Personal characteristics (e.g., low self-esteem) also increase risk but Hamey and Muehlenhard (1991) caution that victim characteristics should not be viewed as factors that cause rape but rather factors that, in interaction with cultural and situational factors, increase the risk for victimization.

This article examines the problem of sexual victimization within the context of homeless and runaway youth. Although homeless and runaway youth experience the same risk factors noted in the sexual assault literature, they experience additional risks. Many are without a stable residence to which they can return. Therefore, they may spend more time on the street, especially at night, which increases their exposure to potential offenders. Some youth also engage in trading sex and prostitution, which may increase their chances of interacting with sexually violent customers. Finally, many homeless and runaway youth participate in deviant subsistence strategies, which is also likely to increase risk. The risk factors listed in the sexual assault literature, in combination with those that are associated with being homeless, are likely to increase the risk of sexual victimization.

In explaining the victimization of homeless and runaway youth, some research has looked to the social context of the environment in which these youth interact (Hagan \& McCarthy, 1997; Hoyt, Ryan, \& Cauce, 1999). Time on the street, interactions with other street youth, and participation in risky, deviant behaviors may be tied to the likelihood of sexual victimization.

The current study uses victimization theories (Cohen \& Felson, 1979; Hindelang, Gottfredson, \& Garofalo, 1978; Miethe \& Meier, 1990) to examine factors that may be associated with the increased risk of sexual victimization. Such theories are useful for studying homeless and runaway youth because they take into account the contextspecific effects of daily street life and the resources and survival needs that the youth bring to this context.

Specifically, lifestyle-exposure theory (Hindelang et al., 1978) and routine-activity theory (Cohen \& Felson, 1979) argue that the lifestyles and daily routines of people's everyday lives are related to differential exposure to dangerous places and people, which creates the potential for crime opportunities and therefore for increased victimization. Victimization theories consist of four central concepts: proximity to crime, exposure to crime, target attractiveness, and guardianship. The concurrence of these four constructs increases the likelihood of being a victim.

Miethe and Meier (1990) developed a structural-choice theory of victimization, which not only examines the context-specific effects of lifestyles and daily routines on the risk for victimization but also takes into account the target selection 
process. Miethe and Meier (1994) retain the four central concepts used in victimization theories but divide them into two propositions. Proximity and exposure are combined into what they call "structural features" because some people are predisposed to riskier situations based on their activities. Guardianship and target attractiveness represent the "choice components" because they determine which targets are ultimately chosen. Thus, living in certain environments increases one's proximity and exposure to dangerous situations, but whether or not an individual becomes a victim depends on his/her subjective utility compared to other targets (Miethe \& Meier, 1994).

Proximity to crime is the physical distance between the areas where potential offenders are found and where potential targets of crime reside (Cohen, Kluegel, \& Land, 1981). It follows that individuals who live in high-crime areas are more likely to have contact with offenders, which increases their risk for victimization.

Homeless adolescents who spend more time on the streets are at greater risk for victimization (Hoyt et al., 1999; Janus, McCormack, Burgess, \& Hartman, 1987; Whitbeck, Hoyt, \& Yoder, 1999). Hoyt and associates (1999) found that the number of months that adolescents had spent homeless was positively associated with victimization. Other studies also have found that the more time adolescents spend on the street, the greater the likelihood of their engaging in dangerous activities (Janus et al., 1987; Kufeldt \& Nimmo, 1987), which increases the risk for victimization.

Being on the streets increases one's accessibility to crime in addition to increasing the likelihood of contact between oneself and potential offenders (Miethe \& Meier, 1994). Moreover, since personal victimization is associated with the amount of time spent in public places, especially at night (Hindelang et al., 1978), runaways are at further risk since much of their time is spent on the streets. Following this, it was expected that adolescents who leave home for the first time at an early age, those who run from home numerous times, and those who spend more time sleeping on the streets are at greater risk for sexual victimization.

Exposure to crime is characterized by an individual's visibility and accessibility to potential offenders (Cohen et al., 1981). Many homeless adolescents engage in highrisk behaviors, often as a means of survival which increases their exposure to offenders, thus resulting in an increased risk for victimization (Hagan \& McCarthy, 1997; Whitbeck \& Hoyt, 1999). Hagan and McCarthy (1997) found that runaway youth were more likely to engage in criminal activity when they lacked food or money or when trying to find shelter (Hagan \& McCarthy, 1997). Adolescents involved in deviant activities also are at greater risk for assault compared to non-delinquents (Lauritsen, Sampson, \& Laub, 1991). A positive association between deviant subsistence strategies and victimization has also been found among homeless adolescents (Whitbeck et al., 1999).

Survival sex may increase a young person's chances for sexual victimization. Many runaways become involved in trading sex because they are hungry and need money (Silbert \& Pines, 1982; Weisberg, 1985). Being on the streets and recruiting potential customers results in these adolescents being highly visible. Trading sex puts homeless young people in dangerous and vulnerable situations with little or no protection from violent customers and others who may try to exploit them. Engaging in risky sexual behaviors is linked to victimization among homeless adolescents (Whitbeck et al., 1999). Substance abuse also has been found to be associated with an increased risk of victimization among homeless males (Hoyt et al., 1999). High rates of drug and alcohol use may put youth in vulnerable situations where their ability to refuse or ward off unwanted advances is diminished by their incapacitated state. 
Furthermore, runaways tend to hang out on the streets where they are exposed to a variety of people, many of whom may be potential victimizers. The lifestyles and daily routines of these adolescents may expose them to potential offenders thereby increasing their chances of becoming victims of sexual assault. Based on the above findings, it was hypothesized that homeless youth who engage in deviant subsistence strategies, have high rates of drug use and engage in survival sex are more likely to be sexually victimized.

Target attractiveness refers to persons or objects selected by the offender because they have particular value (Miethe \& Meier, 1994). For example, femaleness may be an attribute of the victim that is congruent with the needs and motives of a sexual offender (Finkelhor \&Asdigian, 1996); therefore, females are more likely to be victims. Research also finds that runaway females are victimized sexually at a higher rate compared to runaway males (Cauce et al., 2000; Weisberg, 1985; Whitbeck \& Simons, 1990; Whitbeck, Hoyt, \&Ackley, 1997). Age is also positively associated with sexual assault among youth (Finkelhor \& Asdigian, 1996). Finally, youth with kempt physical appearances may be more likely to be chosen as potential victims. Because some research has found that homeless women do their best to look as though they are not homeless so they can spend time in public places (such as stores and hotels) without drawing attention (Russell, 1991), suggests that some homeless youth may be particularly vulnerable. These personal characteristics may increase the likelihood of victimization independent of anything individuals do because such characteristics are congruent with the needs and motives of the offender (Finkelhor \&Asdigian, 1996). Following this, it was expected that females, older adolescents, and those with kempt physical appearances would be more likely to be at risk for sexual victimization.

Capable guardianship is the ability of persons or objects to prevent violations from occurring (Cohen et al., 1981). Guardianship is important because implementing precautions increases the "costs" for the would-be offender, thus decreasing the opportunity for victimization (Miethe \& Meier, 1994). Some research finds that peers play a role in the protection of runaways (Hagan \& McCarthy, 1997) and that street families, which may consist of deviant peers are often formed to provide protection and support. Females frequently join these groups for safety (Hagen \& McCarthy, 1997). Although many street "family members" engage in deviant behaviors, they may provide some level of protection to the group, thereby increasing the level of guardianship, which is important in preventing victimization from occurring (Cohen et al., 1981). Following this, it was hypothesized that youth who affiliate with deviant peers are likely to experience lower rates of sexual victimization.

\section{METHOD}

\section{Participants}

Data are from the Seattle Homeless Adolescent Research and Education Project (SHARE). This is the first wave of an outgoing longitudinal study that follows a prior study of homeless youth in Seattle (cf., Cauce et al., 1998; Hoyt et al., 1999). It is well established that it is not possible to randomly sample homeless populations (Wright, Alien, \& Devine, 1995) since unbiased enumeration is not realistic. Therefore, young people were interviewed using a systematic sampling strategy that maximized locating homeless and runaway youth in metropolitan Seattle. This strategy employed both street intercepts and locale interviewing. The locales, which provided homeless youth with services, were contacted to obtain permission to give interviewers access to youth. Young people were interviewed over a period of two years (February 
1996 to February 1998) by outreach workers who were trained youth workers with considerable experience interviewing and interacting with this group of young people. They were very familiar with local street cultures and were already known and trusted by many of the runaways. Interviewers approached all available youth who passed through or were at the locale and appeared to be between the ages of 13 and 21. Street intercepts were made by approaching youth in the areas of the city known to be frequented by homeless and runaway adolescents. These street intercept interviews were conducted at coffee houses, restaurants, libraries, cafeterias, and outside, if weather permitted. In addition to solicitations by the interviewers, youth also were recruited through flyers posted in the local agencies and group informational meetings held at the agencies.

Youth were first administered a brief "eligibility" interview. If deemed to be eligible, the study and procedures were explained and informed consent was obtained from interested youth. Eligible youth were between 13 and 21 years of age, spoke English, and did not, at the time of the interview, have a stable residence, have a viable home to which they could return, and were not physically in the custody of the state. Unstable residence was further defined and constrained as not living with parents or guardians in the previous week and not having spent more than four nights at home in the past week. Youth staying at foster care or temporarily housed with family were eligible. Also, youth not living in a group home for 45 days or more, or having the potential to stay in a group home for more than 45 days, were eligible. If youth had been on the streets less than one week, parental permission was obtained prior to the interview. In the state of Washington, adolescents can be considered emancipated at the age of 13. In addition to meeting this age criterion, however, youth were considered emancipated only if they were judged as having no significant contact with parents including no longer being financially dependent on them and not having spent any time at home for a week prior to the interview. If the youths met all these criteria, they were considered emancipated and were allowed to provide sole consent.

If young people agreed to participate and complete consent forms, interviewers took the youth to a quiet, private location to conduct the interview. Due to the length of the questionnaire, the interview was conducted in two parts on separate days. Each section took approximately $11 / 2$ to 2 hours to complete. The youth were paid $\$ 10$ for each section with a $\$ 5$ bonus for completing both sections. Thus, they were offered $\$ 25$ for the entire completed interview. The overall response rate was $95 \%$. This study was approved by the Institutional Review Board at the University of Washington.

A total of 372 youth were interviewed. Just over half were male $(\mathrm{N}=203 ; 54.6 \%)$ and $169(45.4 \%)$ were female. Ages at the time of the interview ranged from 12 to 21 with a median of 17 years. In terms of race, $48 \%$ were White, $6 \%$ were African American, 5\% were Native American, 3\% were Hispanic, and 2\% were Asian or Pacific Islander. Thirty-six percent of the sample reported being bi-racial or multi-racial.

\section{Measures}

The Pearson correlation coefficients, means, and standard deviations for all variables used in the present analysis are presented in Table 1.

Age at first run was a single item that asked youth how old they were when they left home for the first time. Many youth were on their own for the first time at a very young age (Mean $=13$ years).

Number of times run was a single item that asked respondents the total number of times that they had ever run away from home (Mean $=9.5$ runs). 


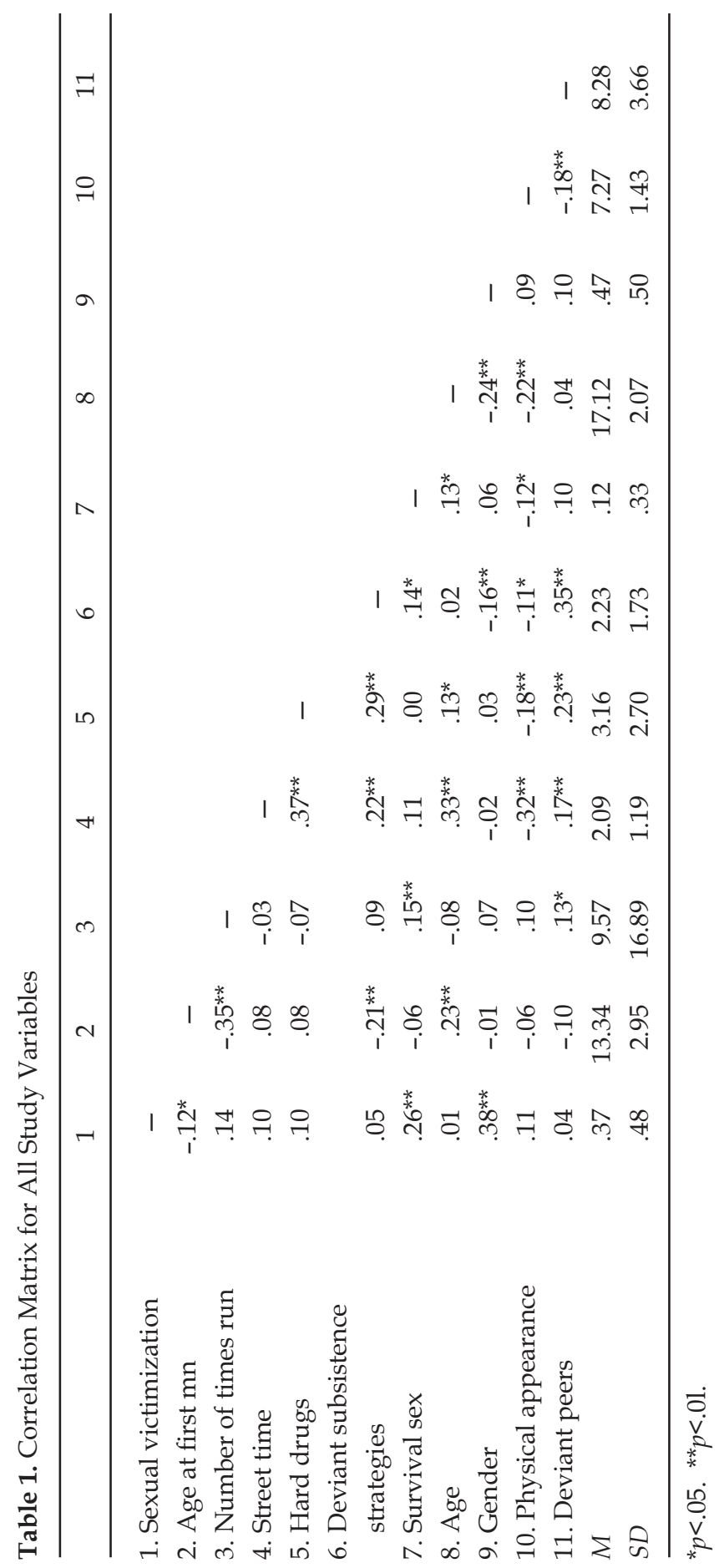


Street time was a single item that asked young people how often they had slept outdoors overnight (not camping) since being on their own. The majority of the sample had slept out on the street on numerous occasions.

Hard drug use was measured using 11 items in which respondents were asked about frequency of use of drugs such as cocaine/crack, acid, mushrooms, ecstasy, and heroin/opium during the past six months. Due to skewness, each of the 11 items were dichotomized $(0=$ no use; $1=$ used the substance at least once) and then summed. The composite measure for hard drugs ranged from 0 to 11 with a mean of 3.2. This indicates that the youths had used approximately three different kinds of substances in the past 6 months. Cronbach's (for the 11 dichotomized items) is .83 .

Deviant subsistence strategies was measured using 6 items that focused on different tactics that adolescents may have used (e.g., conning, robbing) since being on the street in order to survive (adapted from Whitbeck \& Simons, 1990). Due to skewness, each indicator was dichotomized ( $0=$ never; $1=$ at least once) and then summed to form a scale of deviant subsistence strategies. Cronbach's ( for the 6 dichotomized items is) .76.

Survival sex was a single item that asked respondents how often they had traded sex since being on their own. Due to skewness, the item was dichotomized $(0=$ never traded sex; 1 = traded sex at least once). Eleven percent of adolescents reported trading sex at least once.

Deviant peers was measured using 13 items in which young people were asked, for example, if any of their close friends had ever, sold drugs, used drugs, sold sexual favors, or threatened and/or assaulted someone with a weapon $(0=$ no; $1=$ yes $)$ (adapted from Whitbeck \& Simons, 1990). The 13 items were summed and the composite scale ranged from 0 to 13 . Cronbach's a is .87 .

Physical appearance was measured using two items in which interviewers were asked to rate the appearance of the youth after the interview and before examining the completed questionnaire. The two items asked about the respondent's physical appearance including facial and body features, grooming, dress, and cleanliness. The response categories ranged from $1=$ very unattractive to $5=$ very attractive. The two items were summed such that the higher the score, the more kempt/pleasing the physical appearance. The bivariate correlation is .47 .

Age and gender were controlled for in this model. Gender was coded $0=$ males and $1=$ females.

Sexual victimization consisted of six items that focused on whether respondents had any unwanted or unpleasant sexual experiences with people since they have been on their own. For example, "how often has someone ever ..." "had you do something sexual or mess around with you sexually when you didn't want to," "had you touch them sexually when you didn't want to," and "put, or fried to put, anything, or any part of their body into you sexually (like into your vagina, butt, or mouth) when you didn't want them to." Response categories ranged from $0=$ never to $3=$ many times. Due to skewness, each of the six items were dichotomized and then summed. The final measure was also dichotomized (due to skewness) with $0=$ never been sexually victimized and 1 = have been sexually victimized at least once. Overall, $37 \%$ of respondents indicated that they had been sexually victimized since being on their own. Cronbach's a for the six dichotomous items is .81 .

\section{RESULTS}

Table 2 presents the results of the logistic regression model for predictors of sexual victimization among homeless and runaway youth. For interpretation purposes, the unstandardized logistic regression coefficient (B) is the change in the dependent 
variable that is associated with a one-unit change in the independent variable (Menard, 1995). The odds ratio (Exp [B]) is the ratio of the probability that some event will occur divided by the probability that the same event will not occur (Kleinbaum, Kupper, Muller, \& Nizam, 1998). For example, a (B) of .21 for gender with an odds ratio of 2 indicates that females are twice as likely as males to be sexually victimized.

Three blocks of variables are included in the initial model: proximity, exposure, and choice component items. As revealed in Model 1 (Table 2), none of the proximity items (i.e., age at first run, number of times run, and street time) were significant. In terms of exposure, engaging in survival sex significantly increased the odds of becoming a victim of sexual assault $(B=1.71$; Exp $(B)=5.55)$. In fact, young people who traded sex were approximately five and one-half times more likely to be sexually victimized compared to those who did not trade sex. None of the other exposure items was significant in Model 1.

The choice component variables revealed that being female and having a clean/ pleasing physical appearance increased the likelihood of being sexually victimized. That is, females were seven times more likely to be victims of sexual assault compared to males $(B=1.98$; $\operatorname{Exp}(B)=7.21)$ and for each increment in physical appearance, the odds of being a victim increased by 1.31 times. In other words, the more kempt the appearance of youth, the more likely they are to be victimized.

In order to test for the combination of risk factors, three additional models were run (Models 2-4), each including the addition of one interaction term. The interactions were entered separately since collinearity could potentially be a problem (Kleinbaum et al., 1998). Although all possible combinations of the proximity and exposure variables with the choice components were included as interactions, only those that were significant at the .05 level were included in the table.

In order to help interpret the interactions, the logistic regression equation was used to graph the interaction at high, medium, and low levels of a particular variable (e.g., deviant subsistence strategies). These values were set at one standard deviation above the mean, at the mean, and one standard deviation below the mean, respectively. These values were then substituted into the regression equation (Aiken \& West, 1991). In plotting the regression lines, the predicted probabilities were used for the $\mathrm{Y}$ axis (dependent variable) instead of the log odds values as they are easier to interpret.

The interaction term gender $x$ deviant subsistence strategies was positive and significant $(\mathrm{B}=.38$; Exp $(\mathrm{B})=1.47)$. Figure 1 revealed that relative to males, females were more likely to be sexually victimized as their participation in deviant subsistence strategies increased. Females also experienced higher rates of sexual victimization compared to males when participation in deviant subsistence strategies was low. The significance of the interaction term and the direction of the difference indicated that engaging in deviant subsistence strategies increased the risk of sexual victimization for females, but not for males.

The next model added the interaction term gender $\times$ hard drug use which was positive and significant $(B=.22 ; \operatorname{Exp}(B)=1.24)$. As revealed in Figure 2, the effects of drug use on sexual victimization differed by gender. Relative to males, females were more likely to be sexually victimized as their use of hard drugs increased. A test of the individual slopes revealed that females experienced higher rates of victimization as their drug use increased whereas among males, increasing drug use did not affect level of sexual victimization.

The interaction term age $\times$ deviant subsistence strategies was negative and statistically significant $(\mathrm{B}=-.09$; $\operatorname{Exp}(\mathrm{B})=.91)$. The pattern of this interaction effect (see Figure 3), revealed that the effects of deviant subsistence strategies on sexual victimization differed significantly among the three age groups. The younger aged youth 


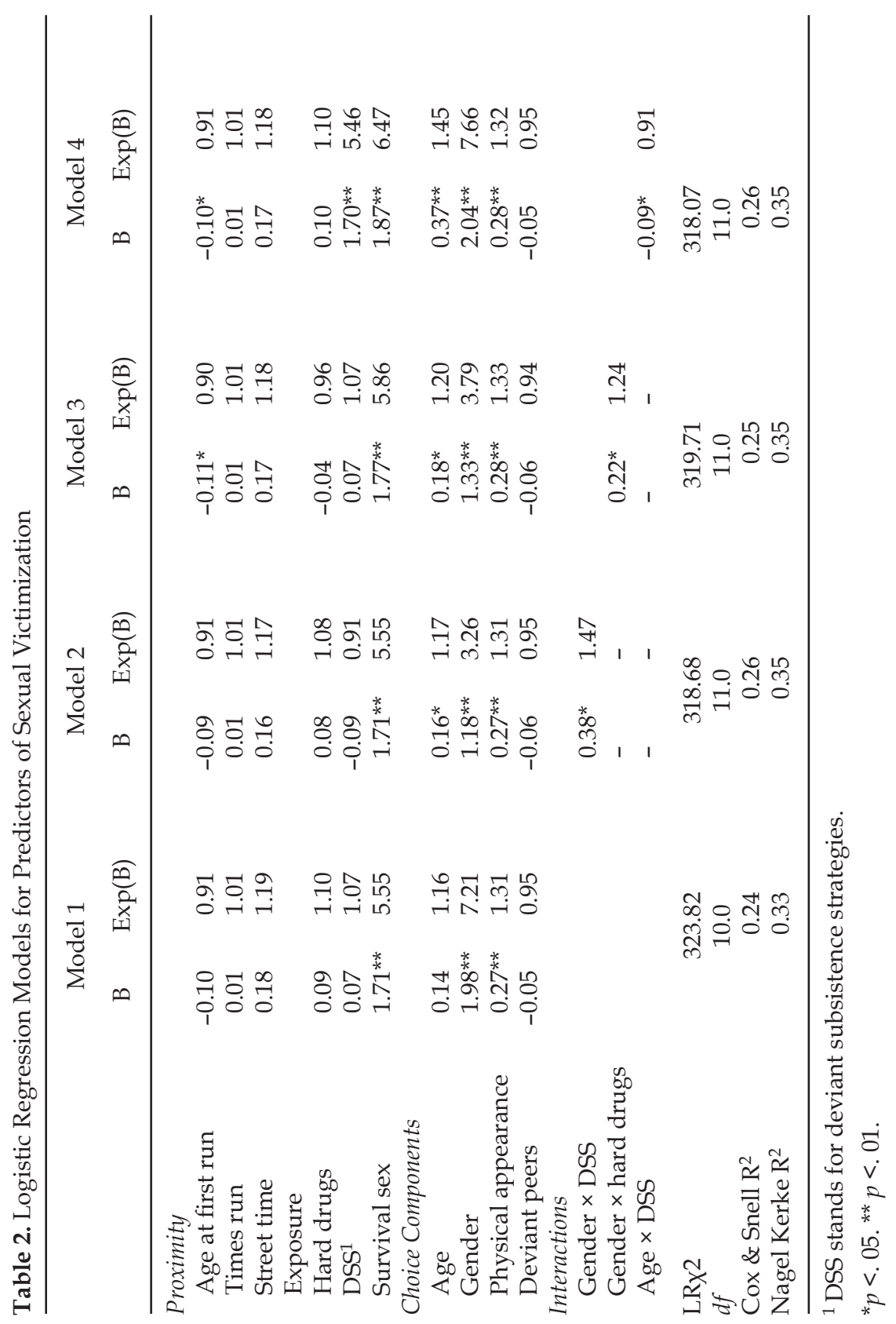




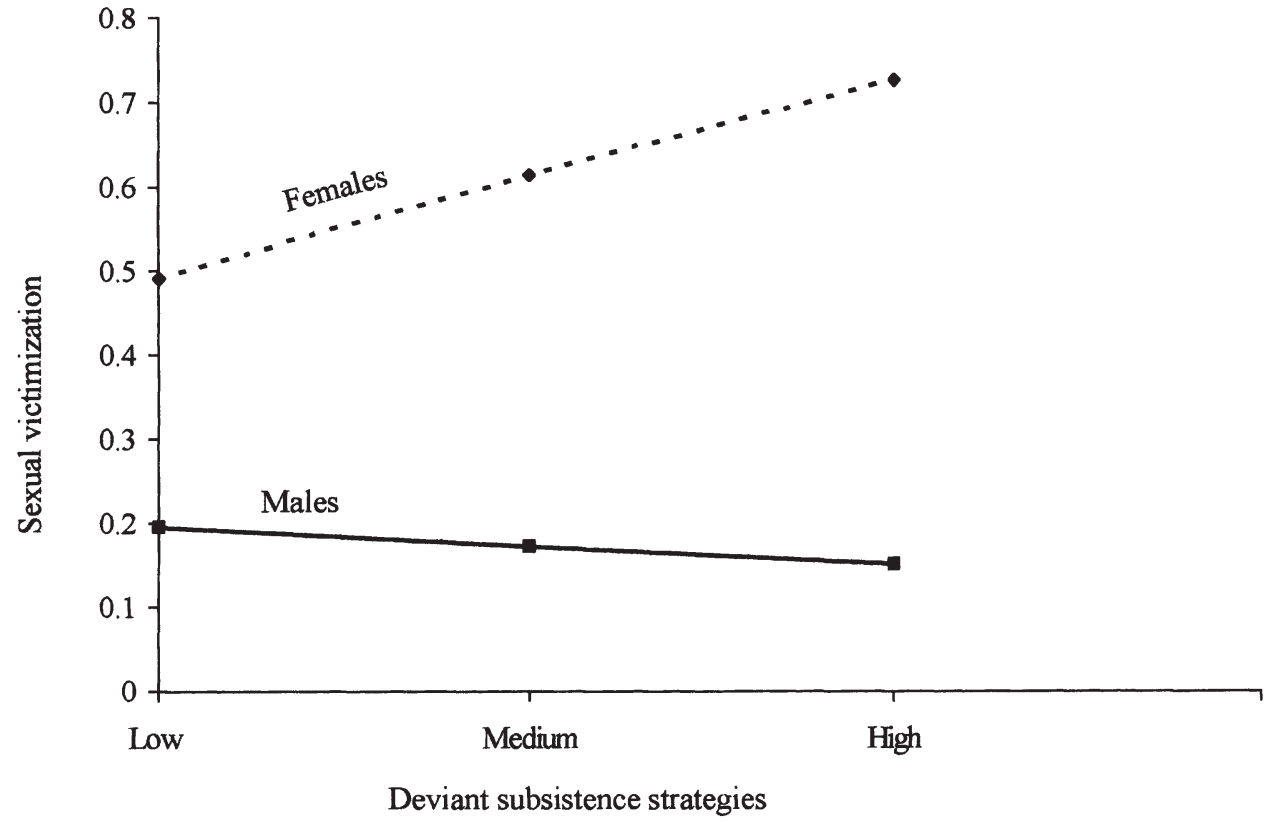

Figure 1. Interaction for gender $\times$ deviant subsistence strategies.

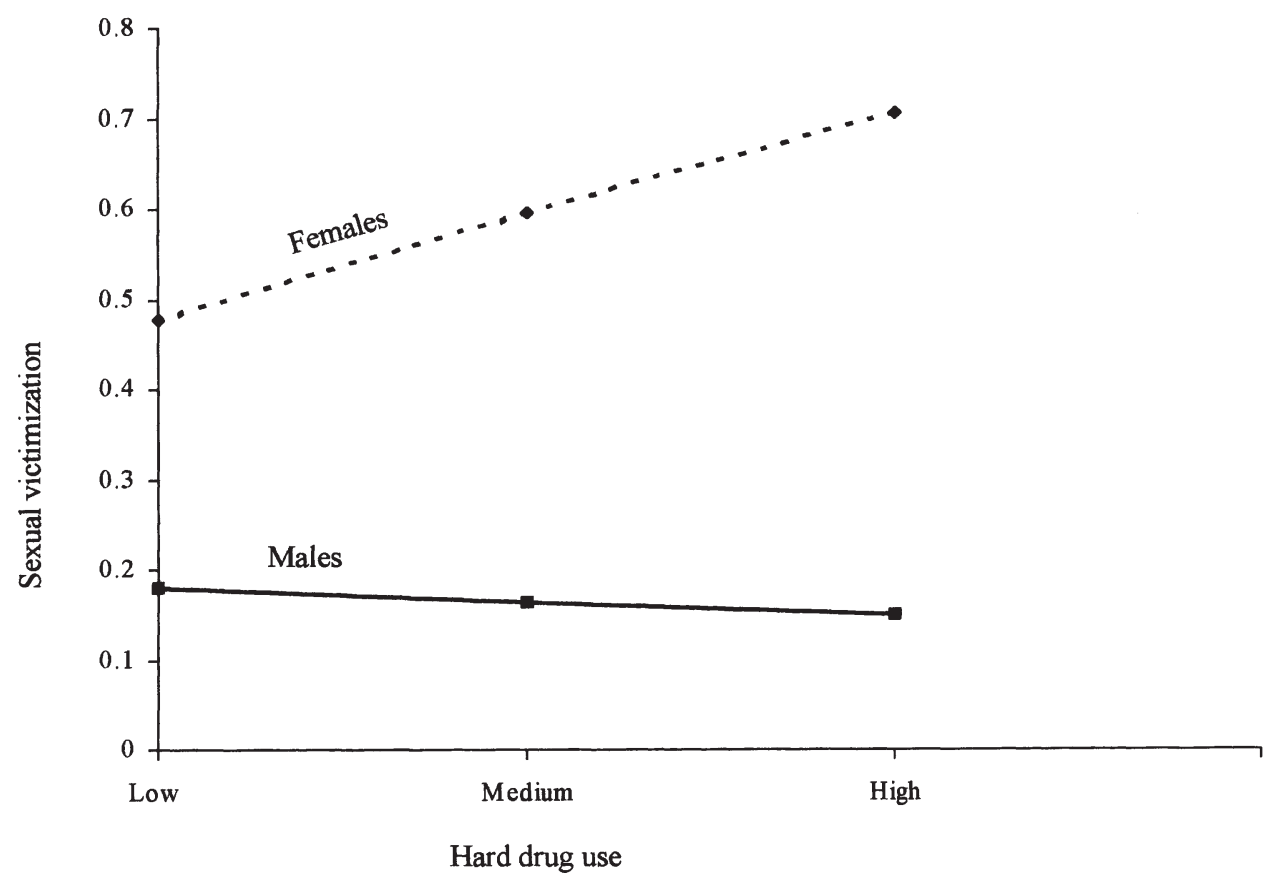

Figure 2. Interaction for gender $\times$ hard drug use. 
experienced the lowest levels of sexual victimization when their participation in deviant subsistence strategies was low. In contrast, 19-year-old youths experienced the highest rates of sexual victimization when participation in deviant subsistence strategies was lowest. For the middle age group, increases in deviant subsistence strategies appeared to have little affect on sexual victimization. Thus, the association between involvement in deviant subsistent strategies and increased risk for sexual victimization appears to be present only among the younger adolescents.

The interaction term physical appearance $\times$ deviant subsistence strategies (results not shown) was significant using a one-tail test criterion $(B=.11$; Exp $(B)=1.11)$. This suggests that those who had kempt physical appearances were more likely to be sexually victimized as participation in deviant subsistence strategies increased.

Chi-square also was significant when comparing the models containing the interaction terms to the main model. This suggests that the interaction terms, which were a combination of the choice components and the exposure items, significantly improved model fit.

\section{DISCUSSION}

The findings from the main effects model revealed that the proximity items (i.e., age at first run, number of times run, and street time) did not significantly predict sex-

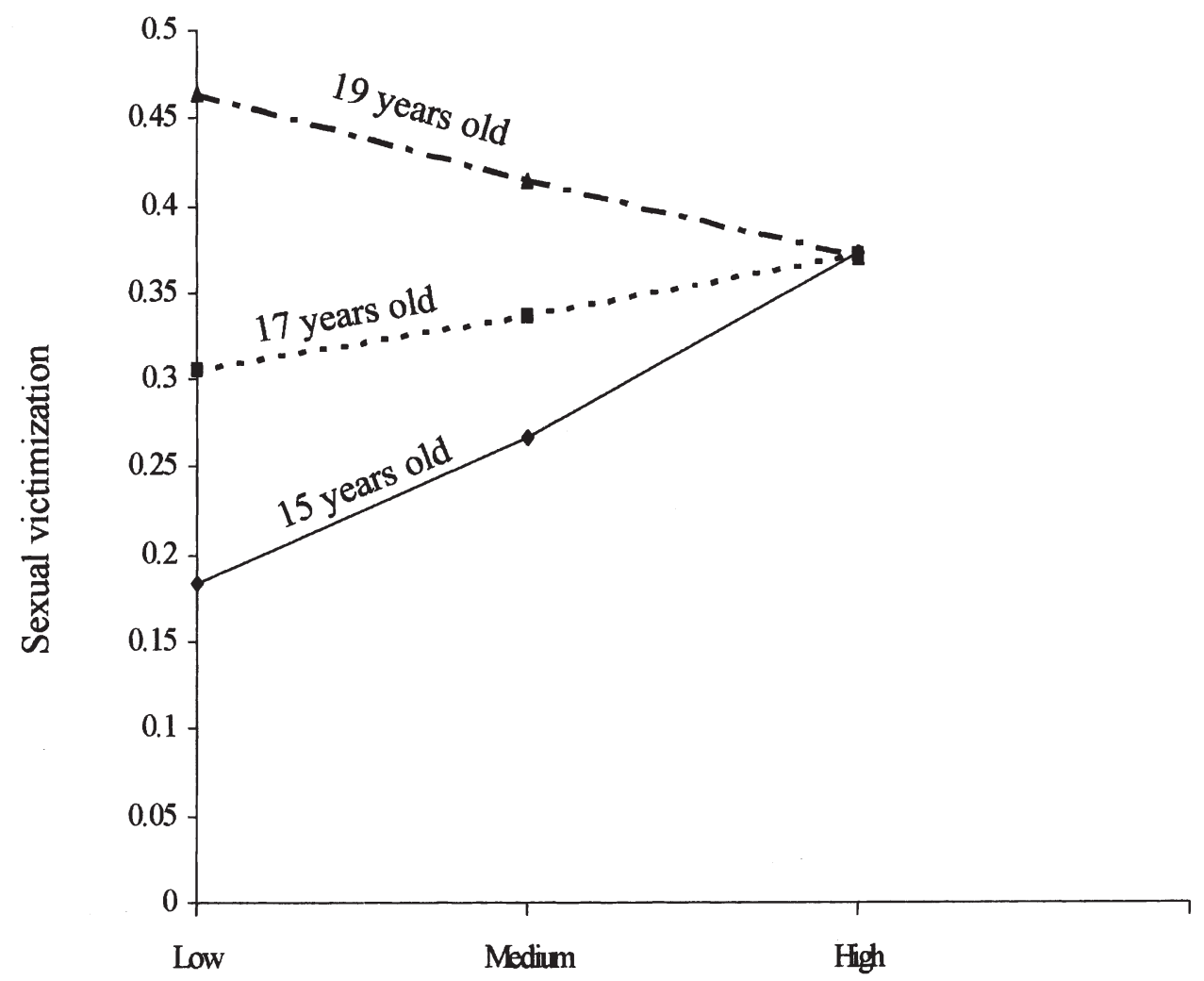

Deviant subsistence strategies

Figure 3. Interaction for age $\times$ deviant subsistence strategies. 
ual victimization, contrary to what was hypothesized. It is noteworthy that in previous models (results not shown), spending time on the street was significant before adding the exposure items into the equation. However, controlling for these other variables suggests that the exposure items exert more of an influence. Another possible explanation for the lack of significance of the proximity items is that being on the street increased risk but since all respondents were homeless, there was little variability across street youth due to the fact that their day-to-day activities are generally carried out in areas that are in close proximity to potential offenders (Hoyt et al., 1999).

Among the exposure items, engaging in survival sex was strongly associated with sexual victimization, which is consonant with previous research on homeless populations (Weisberg, 1985; Whitbeck \& Simons, 1990, 1993). Trading sex means these young people are highly visible and accessible, which makes them vulnerable targets exposed to potential offenders. Thus, the current study provides support for the concept of exposure to crime in predicting the likelihood of sexual victimization.

Hard drug use and deviant subsistence strategies were not significant in the main model, suggesting that they are not risk factors by themselves. However, both variables were associated with an increased risk for sexual victimization when combined with gender and/or age. Thus, even though males and females may engage in similar activities, young women are more likely to be the victims of sexual assault. In other words, engaging in high-risk behaviors predisposes some people to greater risks but it is the combination of these behaviors with gender and/or age that determines who will be chosen as a victim.

Although homeless youth are vulnerable to the same risk factors found in the sexual assault literature (e.g., gender, age, drug use), additional risks exist. For example, due to the small number of options available, many homeless youth engage in criminal activity when they lack food or money or when trying to find shelter (Hagan \& McCarthy, 1997). Engaging in deviant subsistence strategies and survival sex may expose them to potential offenders and increase their risk for sexual victimization. As such, homeless youth experience a greater number of risks due to the social context of the street environment.

In terms of the choice components, gender and physical appearance were associated with sexual victimization. Consistent with the literature on homeless youth/ adolescents and with what was hypothesized, females were sexually victimized at a higher rate compared to males (Cauce et al., 2000; Whitbeck \& Simons, 1990; Whitbeck et al., 1997). This is also consistent with the sexual assault literature, which finds high rates of sexual victimization and rape among college women (Koss et al., 1987). Finally, this finding also supports the work of Finkelhor and Asdigian (1996) in that femaleness is a characteristic congruent with the needs of the sexual offender.

Youth who had clean/pleasing physical appearances also were more likely to have experienced sexual victimization. According to victimization theories, more attractive targets will be chosen over less attractive targets (Miethe \& Meier, 1994). Considering that sexual victimization is our outcome variable, it is plausible that females and those with clean/pleasing physical appearances are viewed as more attractive targets because these are characteristics that are congruent with the needs of the offender (Finkelhor \& Asdigian, 1996); therefore, those who have such characteristics are more likely to become victims. Thus, the current study finds support for the concept of target attractiveness.

Although previous research has found that older youth are more likely to be victimized (Finkelhor \& Asdigian, 1996), we did not find support for this hypothesis. In fact, age alone did not predict sexual victimization. Consistent with the structural-choice the- 
ory of victimization, however (Miethe \& Meier, 1994), combining age with deviant subsistence strategies increased risk. But the current study found that younger individuals, not older youth, were at higher risk. It is possible that younger people are new to the streets and have little experience with street life. This inexperience, coupled with the fact that they engage in deviant subsistence strategies, increases their chances of interacting with potential offenders thereby increasing their risk for sexual victimization.

Even though structural-choice theory holds that guardianship is important for determining which targets are ultimately selected (Miethe \& Meier, 1994), no support was found for this hypothesis. Deviant peers was not associated with sexual victimization. One explanation is that it is difficult to separate out deviant peers and deviant subsistence strategies. The literature demonstrates that affiliating with deviant peers leads to participation in deviant subsistence strategies (cf., Hagan \& McCarthy, 1997; Lauritsen et al., 1991; Whitbeck \& Hoyt, 1999), which may result in exposure to potential offenders and increased risk for victimization. Therefore, if their close friends engage in such behaviors, it is doubtful that they are providing guardianship or protection from victimization to these youth. Due to the nature of the sample, it seems difficult at best to assess the extent of capable guardianship.

Although the structural-choice theory of victimization (Miethe \& Meier, 1990) was useful for explaining the effects of the street environment on the likelihood of sexual victimization among homeless youth, some limitations should be noted. First, the definitions of the four central concepts of victimization theories are vague and overlap, making it difficult to get accurate measures of the indicators. For example, it is possible that grouping street time and age at first run under exposure, rather than proximity, may have given us different results. In addition, the current study was not specifically designed to test the four central concepts; therefore, some indicators may not have directly tapped the constructs. Another limitation lies with some of the measures. For example, "physical appearance" may be subject to interviewer bias and we were unable to check the reliability of this measure. Another example is our sexual victimization variable, where the wording of certain questions may be subject to biases.

Our results have practical implications for those who work with homeless and runaway youth. The high rates of sexual victimization experienced by these youth, particularly females, suggest the need for early interception and intervention. Furthermore, increased funding for shelters, drop-in centers, counselors, and especially street-based outreach workers who can locate these youth and provide them with necessary services is needed. However, it is important to recognize that traditional intervention approaches may not be appropriate for this particular population. Interventions that will be most successful are those that address the broader matrix of problems that these young people present and face (Cauce et al., 1998).

The next step would be to explore in greater detail the positive link that was found between physical appearance and sexual victimization. To date, little research has adequately addressed the concept of target attractiveness and/or target congruence, especially in the area of personal victimization. Better measures of this construct are needed to allow us to more fully understand the victimization process. Future studies on personal victimization may wish to explore more fully the combination of exposure items and choice components to see if the current findings are only unique to homeless populations or if they apply to other populations such as college students.

This study, which focused on the effects of a high-risk environment on the sexual victimization of homeless and runaway youth, has begun to unfold some of the complexities associated with who gets victimized. Although engaging in deviant and risky behaviors increased the risk for sexual victimization, personal characteristics of 
the youth were also significant. Therefore, the likelihood of being a victim is a combination of engaging in certain behaviors and having certain attributes that are considered of value by the offender. This suggests that being victimized is not simply a matter of being on the street (cf., Hoyt et al., 1999) but who you are and what you are doing also matters.

\section{REFERENCES}

Abbey, A., Ross, L. T, McDuffie, D., \& McAuslan, P. (1996). Alcohol and dating risk factors for sexual assault among college women. Psychology of Women Quarterly, 20, 147-169.

Aiken, L. S. \& West, S. G. (1991). Multiple regression: Testing and interpreting interactions. Newbury Park, CA: Sage Publications.

Cauce, A. M., Paradise, M., Ginzler, J. A., Embry, L., Morgan, C., Lohr, Y., \& Wagner, V. (2000). The characteristics and mental health of homeless adolescents: Age and gender differences. Journal of Emotional and Behavioral Disorders, 8, 230-239.

Cauce, A. M., Paradise, M., Embry, L., Morgan, C., Lohr, Y., Theofelis, J., Heger, J., \& Wagner, V. (1998). Homeless youth in Seattle: Youth characteristics, mental health needs, and intensive case management. In K. Kutash, A. Duchnowski, \& M. Epstein (Eds.), Community-based programming for children with serious emotional disturbances: Research and evaluation (pp. 611-632). Baltimore, MD: Brookes Publishing.

Cohen, L. E., \& Felson, M. (1979). Social change and crime rate trends: A routine activity approach. American Sociological Review, 44, 588-608.

Cohen, L. E., Kluegel, J. R., \& Land, K. C. (1981). Social inequality and predatory criminal victimization: An exposition and test of a formal theory. American Sociological Review, 46, 505-524.

Finkelhor, D. (1993). Epidemiological factors in the clinical identification of child sexual abuse. Child Abuse \& Neglect, 17, 67-70.

Finkelhor, D. (1994). Current information on the scope and nature of child sexual abuse. The Future of Children, 4, 31-53.

Finkelhor, D., \& Asdigian, N. L. (1996). Risk factors for youth victimization: Beyond a lifestyle/routine activities theory approach. Violence and Victims, 11, 3-19.

Fromme, K., \& Wendel, J. (1995). Beliefs about the effects of alcohol on involvement in coercive and consenting sexual activities. Journal of Applied Social Psychology, 25, 2099-2117.

Hagan, J., \& McCarthy, B. (1997). Mean streets: Youth crime and homelessness. New York: Cambridge University Press.

Hamey, P. A., \& Muehlenhard, C. L. (1991). Factors that increase the likelihood of victimization. In A. Parrot \& L. Bechhofer (Eds.), Acquaintance rape: The hidden crime (pp. 159-175). New York: John Wiley \& Sons, Inc.

Hindelang, M. J., Gottfredson, M. R., \& Garofalo, J. (1978). Victims of personal crime: An empirical foundation for a theory of personal victimization. Cambridge, MA: Ballinger.

Hoyt, D. R., Ryan, K. D., \& Cauce, A. M. (1999). Personal victimization in a high-risk environment: Evaluating the relative effects of exposure, attractiveness and guardianship. Journal of Research in Crime and Delinquency, 36, 371-392.

Janus, M., McCormack, A., Burgess, A. W, \& Hartman, C. (1987). Adolescent runaways: Causes and consequences. Lexington, MA: Lexington Books. 
Kleinbaum, D. G., Kupper, L. L., Muller, K. E., \& Nizam, A. (1998). Applied regression analysis and other multivariable methods. Pacific Grove, CA: Brooks/Cole Publishing Company.

Koss, M. P., Gidycz, C. A., \& Wisniewski, N. (1987). The scope of rape: Incidence and prevalence of sexual aggression and victimization in a national sample of higher education students. Journal of Consulting and Clinical Psychology, 55, 162-170.

Kufeldt, K., \& Nimmo, M. (1987). Youth on the street: Abuse and neglect in the eighties. Child Abuse \& Neglect. 11, 531-543.

Lauritsen, J. L., Sampson, R. J., \& Laub, J. H. (1991). The link between offending and victimization among adolescents. Criminology, 29, 265-291.

Martin, P. Y, \& Hummer, R. A. (1989). Fraternities and rape on campus. Gender and Society, 3, 457-473.

Menard, S. (1995). Applied logistic regression analysis. Thousand Oaks, CA: Sage Publications.

Miethe, T. D., \& Meier, R. F. (1990). Opportunity, choice, and criminal victimization: A test of a theoretical model. Journal of Research in Crime and Delinquency, 27, 243-266.

Miethe, T. D., \& Meier, R. F. (1994). Crime and its social context: Toward an integrated theory of offenders, victims, and situations. Albany, NY: State University of New York Press.

Russell, B. G. (1991). Silent sisters: A study of homeless women. New York: Hemisphere Publishing Corporation.

Silbert, M. H., \& Pines, A. M. (1982). Entrance into prostitution. Youth \& Society, 13, 471-500.

Vogel, R. E., \& Himelein, M. J. (1995). Dating and sexual victimization: An analysis of risk factors among precollege women. Journal of Criminal Justice, 23, 153-162.

Weisberg, D. K. (1985). Children of the night: A study of adolescent prostitution. Lexington, MA: Lexington Books.

Whitbeck, L. B., \& Hoyt, D. R. (1999). Nowhere to grow. Homeless and runaway adolescents and their families. New York: Aldine de Gruyter.

Whitbeck, L. B., Hoyt, D. R., \& Ackley, K. A. (1997). Abusive family backgrounds and later victimization among runaway and homeless adolescents. Journal of Research on Adolescence, 7, 375-392.

Whitbeck, L. B., Hoyt, D. R., \& Yoder, K. A. (1999). A risk-amplification model of victimization and depressive symptoms among runaway and homeless adolescents. American Journal of Community Psychology, 27, 273-296.

Whitbeck, L. B., \& Simons, R. L. (1990). Life on the streets: The victimization of runaway and homeless adolescents. Youth \& Society, 22, 108-125.

Whitbeck, L. B., \& Simons, R. L. (1993). A comparison of adaptive strategies and patterns of victimization among homeless adolescents and adults. Violence and Victims, 8, 135-152.

Wright, J. D., Alien, T. L., \& Devine, J. A. (1995). Tracking non-traditional populations in longitudinal studies. Evaluation and Program Planning, 18, 267-277.

\section{Acknowledgment}

A version of this article was presented at the American Society of Criminology Meetings in Toronto, November 1999. This article is based on research supported by a grant from the National Institute on Alcohol Abuse \& Alcoholism (AA10253-05), Ana Man Cauce \& Les B. Whitbeck, Investigators. 